\title{
POTENSI DARK TOURISM DI BANDUNG
}

\author{
Dini Rahmawati \\ 0416087703 \\ dini.drm@bsi.ac.id \\ Universitas BSI Bandung
}

\begin{abstract}
Bandung has been famous as a tourist destination or for leisure for a long time since the Dutch colonialism. Most of activities are mass tourism, such as culinary, shopping and nature tourism. Aside from those tourist activities, there is other kind of tourism that actually has been done by tourists and still need to be developed. It's dark tourism. This research aimed to identify the potential of dark tourism and its activity. In this tourism, the object is a place with past dark horrible history for violence experienced by people in the past colonialism. The spectrum of darkest and lightest was demonstrated to show similarity and difference from previous researches as well as the level of eeriness in dark tourism.

This research was conducted in Bandung using qualitative method. Data was obtained by directly visiting the tourist object, interviewed people related to the tourism activity and literature study. The instruments used in collecting data were a camera and a recorder. After processing data, it was then triangulated to make sure that all the result of the data was correct.

From the research it was found that there were one tourist object and one tour included in dark tourism. They were Goa Pakar, consist of Goa Belanda and Goa Jepang, and a ghost tour which was known as Wisata Mistis. Goa Belanda and Goa Jepang are located in Taman Hutan Raya Ir. H. Djuanda or known as Goa Pakar or Dago Pakar. These caves have dark history about the cruelty from struggling against Dutch and Japanese colonialism. While ghost tour is a trip related to visiting spooky places at night. It is expected in the future that the dark tourism object will obtain serious attention and improvement from the local government so that educate tourists about sacrifice of the people who fought for nation independence.
\end{abstract}

Keywords: dark tourism, ghost tour

\section{PENDAHULUAN}

Selama ini pariwisata mengandalkan kegiatan berupa wisata masal (mass tourism) dengan destinasi seperti indoor theme park Trans Studio, Gunung Tangkuban Perahu dan Kawah Putih Gunung Patuha. Selain wisata tersebut, berkembang pula wisata kuliner yang menyuguhkan berbagai macam makanan dan minuman, dari yang jenis lokal hingga asing dan dengan beragam penyajian, rasa dan harga. Ditambah lagi dengan adanya pusat-pusat belanja yang menawarkan berbagai macam benda seperti sepatu, baju, tas dan lain sebagainya yang memiliki beragam model dan harga telah menambah daya tarik wisatawan untuk berkunjung ke Kota Bandung.

Selain berbagai bentuk wisata yang telah disebutkan di atas, ada bentuk wisata lain yang belum dikembangkan di Kota Bandung. Wisata tersebut dinamakan dark 
tourism. Wisata ini memang sangat berbeda dengan wisata lainnya. Ketika wisata lain menyajikan kesenangan dan keindahan dalam kegiatan berwisatanya, dark tourism menyajikan hal-hal yang berkaitan dengan kematian. Di beberapa negara lain seperti Polandia dan Inggris, dark tourism telah berkembang dan menjadi salah satu daya tarik wisata bagi wisatawan yang berkunjung ke negara tersebut. Salah satu contohnya adalah Auschwitch-Birkenau yang berada di Polandia. Tempat ini merupakan sebuah lokasi terjadinya peristiwa holocaust, dimana jutaan bangsa Yahudi dibantai oleh rezim Nazi yang berkuasa pada masa itu. Setelah rezim tersebut runtuh, tempat tersebut dibuka untuk publik sehingga dapat dikunjungi untuk mengenang peristiwa yang pernah terjadi di sana.

Tak kalah dari Polandia dan negara lainnya di Eropa, Kota Bandung juga memiliki tempat-tempat yang terkait dengan kegiatan dark tourism. Hal ini dapat dilihat dari peristiwa sejarah yang pernah terjadi di Kota Bandung pada masa penjajahan Belanda. Di antaranya, adanya peristiwa Bandung Lautan Api yang terjadi saat rakyat mempertahankan Kota Bandung dari rencana Belanda untuk menjadikannya pusat penyimpanan senjata.

Sesuai dengan ciri dark tourism yang merupakan kegiatan wisata yang menyuguhkan hal-hal yang terkait dengan kematian, maka peristiwa masa lalu, baik sejarah maupun suatu peristiwa yang terkait dengan kematian yang tak terlupakan, menjadi pendukung yang sangat besar. Potensi ini dapat dimanfaatkan untuk menambah kegiatan wisata di Kota Bandung sehingga tempat-tempat tersebut dapat lebih bermanfaat, khususnya bagi masyarakat sekitar lokasi, jika dikembangkan secara tepat. Penelitian ini dibatasi hanya pada lokasi yang memiliki nilai sejarah perjuangan kemerdekaan. Alasannya, agar wisatawan yang berkunjung tidak hanya berwisata untuk melihat lokasi dark tourism, tetapi juga mendapatkan pengetahuan sejarah sekaligus mengenang jasa-jasa para pahlawan kemerdekaan yang tidak pernah diketahui namanya. Adapun rumusan masalah dalam penelitian ini yaitu manakah yang berpotensi menjadi obyek wisata dark tourism di Bandung? Adapun tujuan dari penelitian ini adalah untuk mengidentifikasi obyek wisata dan atraksi yang menjadi potensi dark tourism di Bandung.

\section{LITERATURE REVIEW}

\section{Dark Tourism}

Pariwisata merupakan bisnis manusia, budaya dan hospitality, memerlukan SDM dengan posisi, skill, dan job yang tepat. Tantangan utama pariwisata adalah pengembangan kualitas staff. Pariwisata memerlukan network (jaringan) dengan tingkat ketertataan yang mampu menampilkan karakter zona. Dalam zona itu wisatawan bisa mobile dengan lancar dan leluasa untuk memuaskan hasrat konsumsi mereka (Ali Hasan, 2015) dalam berbagai jenis destinasi wisata termasuk dark tourism. Dark tourism adalah perjalanan ke situs-situs yang memiliki tragedi atau kisah atau sejarah tentang kematian manusia secara tragis dan memilukan/mengenaskan dan kegiatan untuk menguatkan ingatan atas peristiwa dan korbannya di situs tersebut (Damanik, 2012). Sharpley (2009) menyatakan bahwa dark tourism adalah perjalanan menuju ke tempat-tempat yang berhubungan dengan kematian, penderitaan dan terlihat mengerikan. Dark tourism merupakan suatu produk wisata berupa 
situs kematian atau bencana yang dikunjungi oleh wisatawan minat khusus. Hal ini berarti situs-situs yang dikunjungi memiliki sejarah masa silam yang terkait dengan kematian yang memilukan dan menyedihkan hingga dikenang banyak orang. Damanik (2012) menyebut wisata ini sebagai wisata kenangan, sedangkan Dini Rahmawati (2015) menyebutnya sebagai wisata kelam.

\section{Penyedia Wisata Kelam}

Stone (2006) membagi-bagi lokasi wisata kelam menjadi 7 lokasi. Tujuannya yaitu untuk membangun kerangka konseptual produk wisata kelam. Tujuh tempat tersebut adalah sebagai berikut:

a. Dark fun factories atau dapat disebut sebagai suatu tempat yang menyenangkan namun kelam. Tempat ini fokus pada hiburan namun dengan menyajikan hal-hal yang mengerikan, contohnya rumah hantu.

b. Dark exhibition atau disebut juga sebagai pameran kelam. Tempat ini menyajikan produk wisata kelam yang berhubungan dengan kematian namun memiliki unsur edukasi, contohnya pameran mayat-mayat yang diawetkan atau juga mumi.

c. Dark dungeon atau disebut juga penjara bawah tanah. Tempat ini menyajikan berbagai jenis hukuman yang diberikan di masa lampau yang dilakukan di ruang bawah tanah dimana penjara dibangun. Contohnya, Galleries of Justice di Nottingham, Inggris.

d. Dark resting places atau dapat disebut sebagai tempat pemakaman. Namun, pemakaman ini bukanlah pemakaman biasa, melainkan suatu pemakaman yang bersifat historis, konservasi dan untuk memperingati suatu peristiwa. Contohnya, kompleks pemakaman di Hollywood tempat banyak selebriti dimakamkan.

e. Dark shrines atau juga disebut tempat keramat. Tempat ini sebenarnya bukanlah merupakan tempat yang dimaksudkan untuk berwisata dan hal ini dapat terlihat dari minimnya infrastruktur yang ada di tempat tersebut. Tempat ini cenderung dimak-sudkan untuk mengingat dan menghormati suatu peristiwa kematian yang terjadi di masa lalu.

f. Dark conflict sites atau tempat konflik. Tempat ini merupakan suatu tempat bersejarah bekas peristiwa peperangan di masa lalu. Awalnya, lokasi ini bukanlah merupakan sebuah tempat wisata, namun karena mengalami komodifikasi maka menjadi sebuah tempat wisata yang potensial. Contohnya, tur ke tempat bekas perang sipil di Gettysburg, Amerika Serikat.

g. Dark camp of genocide atau kamp genosida. Tempat ini merupakan lokasi terjadinya pembantaian yang ekstrim dan bencana. Lokasinya berada di tempat peristiwa tersebut terjadi. Contohnya, lokasi yang dikenal dengan peristiwa yang bernama Killing Field yang terjadi di Desa Cheoung Ek, Phnom Pen, Kamboja.

\section{Konsep Wisata Kelam}

Dari berbagai konsep dark tourism, terdapat dua konsep yang terdapat dalam penelitian ini, yaitu atrocity dan fright tourism. Hal ini sesuai dengan potensi yang telah tersedia di Kota Bandung, yaitu Goa Belanda dan Ghost Tour. Pertama, atrocity 
diterjemahkan sebagai kekejaman yang dilakukan oleh sekelompok orang atau rezim yang melampaui batas kemanusiaan (Damanik, 2012). Ashworth dan Hartmann (2005) menyatakan bahwa atrocity merupakan kombinasi wisata yang marketable yaitu yang memberikan edukasi dan kesenangan serta memiliki kekuatan untuk menyampaikan pesan-pesan yang bersifat politis dan sosial. Jadi, konsepnya adalah suatu tempat bekas terjadinya suatu peristiwa kekejaman yang dilakukan oleh sekelompok orang terhadap manusia lain dan memberikan edukasi kepada wisatawan yang berkunjung. Kedua, fright tourism merupakan wisata dimana para wisatawan mencari sesuatu yang menegangkan atau menakutkan dari pengalaman berwisata yang diperolehnya (Bristow dan Newman, 2004 dalam Sharpley, 2009). Pengalaman tersebut tidak harus diperoleh dari sesuatu yang berkaitan dengan kematian.

\section{Potensi Wisata}

Potensi merupakan suatu daya tarik atau kekuatan yang dimiliki oleh suatu objek yang masih mungkin untuk dapat dikembangkan. Jika dikaitkan dengan wisata, potensi dapat dikatakan sebagai suatu aset yang dimiliki oleh suatu daerah tujuan wisata yang dimanfaatkan untuk kepentingan ekonomi dengan tidak mengesampingkan sosial budaya (Yoeti, 2006). Maka dari itu, potensi wisata dapat dikatakan sebagai sebuah produk yang berpeluang untuk berkembang.

Pitana dan Diarta (2009) menyatakan bahwa ada 4 jenis potensi terkait pengembangan potensi pariwisata, yaitu: (1) potensi alam yaitu seperti hutan, goa, sungai dan sebagainya; (2) potensi kebudayaan, yaitu seperti adat istiadat, kebiasaan hidup masyarakat; (3) potensi manusia, seperti debus; (4) potensi minat khusus, yaitu suatu daya tarik wisata yang lebih spesifik bagi wisatawan, contohnya panjat tebing, menyelam.

Dark tourism merupakan salah satu dari wisata minat khusus yang masih berpotensi untuk dikembangkan. Tanpa disadari, wisatawan sebenarnya telah melakukan kegiatan wisata tersebut. Namun lokasi dan kegiatan wisata tersebut belum dikembangkan secara maksimal sesuai temanya agar dapat menarik wisatawan untuk datang dan mendapatkan pengalaman berwisata yang berbeda dari kegiatan wisata masal pada umumnya.

\section{METODE PENELITIAN}

Metode yang digunakan dalam penelitian ini adalah metode kualitatif. Dalam hal ini, penulis melakukan eksplorasi langsung ke tempat penelitan untuk mendapatkan data primer mengenai Goa Belanda dan Goa Jepang. Di samping itu, penulis juga mengikuti program ghost tour sebanyak 3 kali untuk penelitian ini. wawancara juga dilakukan pada penjaga goa, beberapa orang penyelenggara ghost tour dan wisatawan ghost tour. Sebagai tambahannya, penulis memperoleh data dari literature-literatur yang terkait dengan penelitian yang sedang dilakukan.

\section{HASIL PENELITIAN DAN PEMBAHASAN}

\section{Goa Belanda}

Goa Belanda dibangun di lokasi yang secara geografis memiliki keunikan, yaitu di sebelah selatan patahan Lembang dan berada di titik strategis dari sisa-sisa letusan Gunung Api Sunda yang meninggalkan banyak pecahan, dataran dan gununggunung kecil seperti Burangrang dan Tangkuban Perahu. Maka dari itulah, 
daerah sekitar Goa Belanda sangat subur dan dilewati jalur sentral air yang menjadi penyangga kebutuhan air Kota Bandung.

Goa Belanda merupakan sebuah situs bersejarah peninggalan penjajahan Belanda yang dibuat oleh manusia melalui kerja paksa yang banyak memakan korban. Para pekerja itu tidak hanya mengorbankan kehormatannya, tetapi juga darah dan nyawa. Goa ini dibangun dengan cara menggali bukit hingga membuat lorong tembus yang jaraknya lebih dari 100 meter. Semula kawasan Taman Hutan Raya (Tahura) Ir. H. Djuanda yang menjadi lokasi Goa Belanda berada ini merupakan bentangan pegunungan dari barat sampai ke timur yang berupa sebuah "tangki air raksasa alamiah" untuk cadangan air di musim kemarau. Kemudian pada tahun 1906 dibuatlah sebuah goa yang berfungsi sebagai terowongan penyadapan air Sungai Cikapundung untuk pembangkit listrik tenaga air (PLTA) yang dibuat oleh BEM (Bandoengsche Electriciteit Maatschappij). Pembangunan ini tak lepas dari perkembangan Kota Bandung yang saat itu menjadi kotapraja dengan penduduk yang jumlahnya mencapai lebih dari 47.000 jiwa. PLTA ini merupakan PLTA yang pertama di Indonesia.

Pada tahun 1918 terowongan tersebut beralih fungsinya. Pihak Belanda menjadikan terowongan ini sebagai benteng atau markas militernya. Pemilihan ini dilihat dari letaknya yang tersembunyi dan strategis karena dekat dengan pusat Kota Bandung. Sementara itu, sistem PLTA dibangun kembali dengan perubahan jalur penyadapan yang tak lagi melalui terowongan, melainkan melalui saluransaluran air bawah tanah hingga muncul kembali di permukaan tanah, yang sekarang tepat di pintu masuk Tahura. Selanjutnya air tersebut ditampung di kolam tendon yang dikenal dengan nama Kolam Pakar.

Menjelang Perang Dunia II sekitar tahun 1941 kegiatan militer Belanda semakin meningkat. Oleh karena itu, maka terowongan yang hanya memiliki panjang 144 meter dan lebar 1,8 meter itu mengalami restorasi, yaitu dengan membangun jaringan goa sebanyak 15 lorong dan 2 buah pintu masuk setinggi 3,20 meter. Luas pelataran yang dipergunakan untuk goa seluas 0,6 hektar sedangkan luas keseluruhan goa kira-kira 547 meter persegi. Markas angkatan perang Hindia Belanda dan pusat komando militer tentara Sekutu (Amerika Serikat, Inggris, Belanda, Australia dan New Zealand) ditempatkan di Bandung yang merupakan benteng pertahanan terakhir bagi Belanda.

Goa Belanda ini juga dijadikan sebagai stasiun radio telekomunikasi Belanda, karena stasiun radio yang ada di daerah Malabar Gunung Puntang letaknya di udara terbuka sehingga rawan dari serangan udara. Pada awal Perang Dunia ke II, panglima perang Hindia Belanda Letnan Jenderal Ter Poorten melalui Laksamana Madya Helfrich berkomunikasi dengan panglima armada Sekutu Laksamana Muda Karel Doorman untuk mencegah masuknya Angkatan Laut Kerajaan Jepang yang mengangkut pasukannya mendarat di Pulau Jawa. Namun sayang, usaha tersebut mengalami kegagalan. Akhirnya seluruh pasukan Angkatan Laut Kerajaan Jepang itu berhasil mendarat di bawah komando Letnan Jenderal Hitosi Imamura. Dengan masuknya Jepang, maka Goa Belanda kemudian diambil alih oleh Jepang. Kemudian Jepang bermaksud untuk memperluas goa dengan membuat jaringan goa baru di dekat Goa Belanda dengan cara kerja paksa. Namun, sebelum jaringan goa itu selesai, Indonesia meraih kemerdekaannya 
sehingga Jepang dengan terpaksa harus meninggalkan Indonesia, termasuk Bandung.

Lorong-lorong di Goa Belanda di antaranya digunakan sebagai tempat beristirahat para tentara Belanda, lorong tahanan atau penjara, lorong interogasi tahanan serta lorong distribusi logistik dengan panjang sekitar 100 meter dan lebar 3,2 meter. Seluruh lorong memiliki tinggi sekitar 3 meter. Untuk sirkulasi udaranya, terdapat saluran ventilasi yang dibangun sepanjang 126 meter dengan lebar 2 meter. Saluran ventilasi ini letaknya berdekatan dengan lorong interogasi dan terpisah jauh dari lorong tahanan. Hal ini dimaksudkan agar teriakan gerilyawan perang yang sedang digali informasinya oleh tentara Belanda menggema ke lorong ventilasi. Di langitlangit goa terdapat bekas tempat pemasangan alarm sebagai tanda peringatan untuk mulai bekerja dan berhenti bekerja pada zaman dulu. Kemudian ada juga bekas penerangan lampu yang kini sudah tidak terpakai lagi. Karena itu, suasana di dalam goa ini sangat gelap sehingga bagi mereka yang akan memasuki goa harus mengguna-kan senter. Jika wisatawan tidak membawa senter, mereka dapat menyewanya tepat di depan pintu masuk goa dengan tarif Rp. 5.000 per senter. Hal lainnya yang dapat ditemukan di dalam Goa Belanda yaitu rel troli pengangkutan barang atau sejenisnya yang memanjang di dalam lorong goa menghubungkan Dago Pakar dan daerah Maribaya Lembang.

\section{Ghost Tour}

Menurut Thompson (2010) ghost tour merupakan wisata yang menghubungkan manusia dengan dunia roh. Ghost tour dikonsumsi sebagai bentuk hiburan untuk bersenang-senang dengan memberikan pengalaman yang berkaitan dengan emosi negatif para pengunjung yaitu perasaan takut (Garcia, 2012).

Ghost tour di Bandung merupakan sebuah kegiatan perjalanan wisata yang dilakukan pada malam hari dengan obyek yang dikunjungi tidak hanya memiliki cerita seram dan cerita mitos, tetapi juga mempunyai cerita sejarah. Wisata ini menjadi sarana bagi wisatawan yang ingin langsung berhadapan dengan makhluk gaib atau horor. Semakin seram suasana di lokasi wisata, akan semakin menyakinkan para wisatawan bahwa mereka akan berhadapan dengan makhluk gaib. Wisata ini memang tidak menjanjikan wisatawan untuk dapat secara langsung melihat makhluk gaib atau hantu. Namun, paling tidak, wisatawan dapat merasakan sendiri suasana seram dan kehadiran makhluk gaib yang menghuni lokasi obyek yang dikunjungi.

Ghost tour dilakukan setiap malam minggu pada minggu kedua dan keempat. Wisata ini diselenggarakan oleh sebuah komunitas yang bernama Komunitas Wisata Mistis. Lokasi ghost tour biasanya berpindah-pindah, tergantung pada informasi yang diterima oleh Komunitas Wisata Mistis mengenai lokasi wisata yang belum dieksplor dan memiliki cerita menyeramkan. Namun, tidak menutup kemungkinan lokasi wisata yang dikunjungi berdasarkan permintaan khusus dari rombongan wisatawan. Ghost tour dimulai pada jam 10 malam hingga kira-kira jam 2 dinihari. Bagi wisatawan yang akan mengikuti wisata ini, mereka diharuskan datang pada hari Rabu malam di tempat komunitas tersebut berkumpul. Namun bagi wisatawan yang berasal dari luar kota, mereka diperbolehkan datang sebelum 
wisata dilakukan. Hal ini dilakukan untuk memberikan pengarahan pada wisatawan apa yang boleh dan dilarang dilakukan pada saat ghost tour berlangsung agar semua dapat berjalan dengan baik.

Dalam ghost tour, wisatawan tidak hanya diajak untuk berjalan-jalan ke tempat yang menyeramkan, tetapi ada 3 kegiatan lainnya yang diikuti oleh wisatawan, yaitu:

1. Penelusuran sejarah. Pada sesi ini wisatawan mendapatkan penjelasan mengenai sejarah yang berkaitan dengan lokasi yang dikunjungi. Penjelasan dapat diperoleh baik dari pengurus tempat atau juru kunci maupun dari penyelenggara wisata yaitu Komunitas Wisata Mistis.

2. Penlusuran mitos. Pada sesi ini wisatawan mendapatkan cerita-cerita mitos dan seram yang beredar di lokasi wisata yang dikunjungi. Penjelasan ini diperoleh selain dari juru kunci atau pengurus tempat wisata, juga dari sekelompok orang yang memiliki kemampuan supernatural yang berasal dari Komunitas Wisata Mistis. Kelompok ini dinamakan sebagai Tim Metafisik. Mereka terdiri dari orang-orang yang dapat melihat dan berkomunikasi dengan para makhluk gaib yang dipercaya menempati tempat wisata yang dikunjungi.

3. Aktifitas paranormal. Pada sesi ini, bagi wisatawan yang merasa penasaran terhadap keberadaan makhluk gaib di tempat wisata yang dikunjungi dapat berinteraksi dengan mereka. Sesi ini terdiri dari 3 bagian, yaitu:

a. Uji nyali, yaitu suatu kegiatan yang mana wisatawan ditingkatkan kepekaannya dan dibuka indera keenamnya dengan cara khusus oleh tim metafisik. Kemudian wisatawan tersebut ditempatkan di titik paling seram sendirian di tempat wisata tersebut agar dapat melihat atau bahkan merasakan keberadaan dan kehadiran makhluk gaib di sana.

b. Buka tirai, yaitu kegiatan saat wisatawan ditingkatkan kepekaan-nya dan dibuka indera keenamnya secara khusus oleh tim metafisik. Namun pada bagian ini, wisatawan tidak ditempatkan sendirian di titik terseram. Wisatawan bebas memilih tempat manapun untuk mereka merasakan kehadiran atau bahkan melihat makhluk gaib.

c. Mediumisasi, yaitu kegiatan saat salah satu tim metafisik memasuk-kan makhluk gaib ke dalam tubuh-nya sehingga dapat diajak untuk berkomunikasi oleh wisatawan. Pada bagian ini, wisatawan boleh mengajukan pertanyaan terkait dengan obyek wisata yang dikun-jungi.

Tabel 1. Spektrum dark tourism (Stone 2006)

\begin{tabular}{|l|l|l|l|l|l|}
\hline $\begin{array}{l}\text { Paling } \\
\text { Kelam }\end{array}$ & $\begin{array}{l}\text { Lebih } \\
\text { Kelam }\end{array}$ & Kelam & Cerah & $\begin{array}{l}\text { Lebih } \\
\text { Cerah }\end{array}$ & $\begin{array}{l}\text { Paling } \\
\text { Cerah }\end{array}$ \\
\hline
\end{tabular}

Stone (2006) menyajikan spektrum dark tourism untuk memilah-milah atraksi wisata dalam dark tourism berdasarkan tingkat kekelamannya. Kelompok yang paling kelam dalam spectrum menunjukkan bahwa obyek wisata tersebut merupakan situs kematian yang otentik, berorientasi pada pendidikan, memiliki pengaruh politik 
dan ideology yang tinggi serta dijadikan sebagai pusat sejarah atau konservasi. Sedangkan pada kelompok yang paling cerah dalam spectrum menunjukkan bahwa obyek wisata tersebut merupakan situs yang terkait dengan kematian. Artinya obyek wisata tersebut bukanlah tempat kejadian dimana kekejaman yang berakibat kematian itu terjadi sehingga bukan merupakan produk otentik. Selain itu, obyek wisata tersebut berorientasi untuk hiburan, bersifat komersial dengan infrastruktur yang telah mapan. Pengaruh politik dan unsure ideologi juga sangat rendah.

Dilihat dari sejarah pembentukan Goa Belanda dan Jepang maka dapat disimpulkan bahwa goa tersebut ke dalam spectrum yang paling kelam dalam spectrum dark tourism. Alasannya, Goa Belanda dan Jepang tersebut dibuat dari hasil kerja paksa masyarakat pada masa penjajahan. Dalam pembangunannya banyak terjadi penyiksaan dan berakibat kematian. Di samping itu, salah satu lorong dalam goa tersebut juga dijadikan sebagai tempat untuk menginterogasi para pejuang yang disertai dengan penyiksaan dan dapat berakibat kematian. Ditambah lagi adanya ruang-ruang tahanan yang sangat tidak manusiawi.

Saat ini Goa Belanda dan Jepang merupakan obyek wisata yang banyak dikunjungi wisatawan terutama pada saat akhir pekan. Goa Belanda umumnya menjadi jalan tembus bagi wisatawan yang ingin menuju obyek wisata air terjun di Maribaya dengan berjalan kaki. Sedangkan untuk Goa Jepang, wisatawan hanya berkeliling di dalamnya karena memang goa ini belum selesai dibangun sehingga tidak menjadi jalan tembus menuju kemana pun. Hal yang sangat disayangkan adalah ditemukan coretan-coretan tangan jahil di dinding Goa Belanda, serta adanya beberapa besi-besi yang hilang yang menjadi peninggalan sejarah goa tersebut. Namun demikian, masih ada sisa-sisa tanda sejarah lainnya seperti bekas dudukan lampu-lampu, rel lori, lorong-lorong ventilasi udara,

Berbeda halnya dengan ghost tour. Stone (2006) menganggap ghost tour sebagai suatu wisata yang bersifat hiburan dan komersial untuk bersenang-senang namun tidak lepas dari tema yang terkait dengan kematian. Pemandunya menggunakan humor untuk menghibur wisatawan dan menyisipkan cerita fiksi ketika sedang memandu. Oleh karena itu ia menempatkan ghost tour pada spectrum paling cerah pada spectrum dark tourism.

Hal ini sangat berbeda dengan wisata horor yang penulis temukan di Bandung. Walaupun pihak Komunitas Wisata Mistis tidak menjanjikan wisatawan untuk melihat makhluk gaib atau hantu, namun mereka menghadirkannya sehingga wisatawan mendapatkan pengalaman yang terkait dengan kegiatan supernatural. Selain itu, kisah sejarah dan kisah peristiwa mengenaskan di obyek wisata juga disajikan sehingga wisata ini memberikan pengetahuan kepada wisatawan. Obyek wisata horor langsung berada di tempat dimana terjadi peristiwa mengenaskan atau kematian dan sejarah. Lokasi obyek tidak selalu berada di sebuah kawasan wisata, seperti Goa Belanda yang berada di kawasan Tahura, tetapi bisa juga berada di ruang publik seperti taman kota, rumah sakit atau sekolah. Oleh karena itu, penulis bermaksud untuk menempatkan wisata horor di Bandung pada spektrum kelam cerah pada spektrum wisata kelam Stone (2006). Alasannya, posisi tersebut berada di tengah antara kategori kelam dan cerah karena selain bersenang-senang 
terdapat juga unsur edukasi dan keseraman bukan kondisi yang dibuat oleh penyelenggara wisata melainkan suasana yang memang muncul di obyek wisata.

Tabel 2. Goa Belanda, Goa Jepang dan Ghost Tour dalam Spektrum Dark Tourism

\begin{tabular}{|c|c|c|c|c|c|}
\hline $\begin{array}{l}\text { Paling } \\
\text { Kelam }\end{array}$ & $\begin{array}{l}\text { Lebih } \\
\text { Kelam }\end{array}$ & Kelam & Cerah & $\begin{array}{l}\text { Lebih } \\
\text { Cerah }\end{array}$ & $\begin{array}{l}\text { Paling } \\
\text { Cerah }\end{array}$ \\
\hline $\begin{array}{r}\text { Goa } \\
\text { da } \\
\mathrm{Je}\end{array}$ & $\begin{array}{l}\text { Belanda } \\
\text { Goa } \\
\text { ang }\end{array}$ & & $\begin{array}{l}\text { t tour } \\
\text { di } \\
\text { dung }\end{array}$ & & \\
\hline
\end{tabular}

Diolah dari data primer dan adaptasi dari Stone (2006)

\section{KESIMPULAN DAN REKOMENDASI}

\section{Kesimpulan}

Potensi dark tourism di Bandung terdiri dari obyek wisata Goa Belanda dan Goa Jepang dan ghost tour. Goa Belanda dan Goa Jepang merupakan goa yang menyimpan kisah pada masa penjajahan dimana peristiwa mengenaskan yang mengakibatkan kematian terjadi baik pada masa pembangunannya maupun pada saat penggunaannya. Goa ini termasuk ke dalam spectrum paling kelam dalam spectrum dark tourism. Ghost tour merupakan suatu perjalanan wisata ke tempat-tempat seram. Atraksi yang disuguhkan dalam ghost tour yaitu penelusuran sejarah, penelusuran mitos dan aktifitas paranormal. Meskipun Komunitas Wisata Mistis sebagai penyeleng-gara tidak menjanjikan kepada wisatawan untuk dapat melihat makhluk gaib atau hantu, namun mereka menghadirkan makhluk gaib tersebut dan wisatawan berharap paling tidak dapat merasakan kehadirannya. Penulis menempatkan wisata ini pada kategori kelam cerah dalam spectrum dark tourism.

\section{Rekomendasi}

Diharapkan dengan adanya potensi wisata ini, pemerintah daerah setempat dapat melakukan pembenahan dan pengembangan, khususnya di Goa Belanda dan Jepang, agar wisatawan mendapatkan lebih banyak informasi yang edukatif ketika sedang berkunjung. Begitu juga untuk ghost tour, diharapkan dinas dan instansi terkait dapat memberikan kemudahan izin ketika ghost tour melakukan kegiatannya di tempat-tempat yang memerlukan izin resmi.

\section{REFERENSI}

Ali Hasan, 2015. Tourism Marketing. Yogyakarta: Centere for Academic Publishing Service.

Ashworth, G. dan Hartmann, R. 2005. Horror and Human Tragedy Revisited: The Management of Sites of Atrocities for Tourism. New York: Cognizant Communication Corporation.

Dini Rahmawati. 2015. Potensi Wisata Horor di Kota Bandung. Tesis: Sekolah Pascasarjana Universitas Gadjah Mada, Program Studi Magister Kajian Pariwisata.

Garcia, B.R. 2012 Management Issues in Dark Tourism Attraction: The Case of Ghost Tours in Edinburgh and Toledo. Journal of Unconventional Parks, Tourism \& Recreation Research. 4. 14 - 19.

I Gde Pitana. dan I Ketut Surya Diarta. 2009. Pengantar Ilmu Pariwisata. Yogyakarta: Andi.

Janianton Damanik. 2012. Tipologi Dark

Tourism. Jakarta: Kementrian Pariwisata dan Ekonomi Kreatif.

Oka Yoeti. 2006. Tours And Travel Marketing. Jakarta: Pradnya Paramita. 
Sharpley, R. 2009. Shedding Light on Dark Tourism: An Introduction dalam: R. Sharpley dan P. Stone (ed): The Darker Side of Travel: The Theory and Practice of Dark Tourism. Bristol: Channel View Publications. hal. 3 - 22.

Stone, P.R. 2006 A Dark Tourism Spectrum: Towards A Typology Death and Macabre Related Tourist Sites, Attractions and Exhibition. An Interdisciplinary International Journal. 54 (2). 145-160.

Thompson, R.C. 2010. Am I Going to See a Ghost Tonight?: Gettysburg Ghost Tours and the Performance of Belief. The Journal of American Culture. 33. $79-91$.

\section{Sumber Internet}

http://www.maribayabandung.com/2014/08

/goa-belanda-di-taman-hutanraya.html

(diakses tanggal 26 April 2017)

http://tahuradjuanda.jabarprov.go.id/obyekwisata-alam/goa-belanda/

(diakses tanggal 26 April 2017)

www.wisatamistis.com (diakses tanggal 26

April 2017) 